EVS28

KINTEX, Korea, May 3-6, 2015

\title{
Increasing The Environmental Potential Of Electric Vehicles And Renewable Energies With Grid Attached Energy Storage
}

\author{
Luis Oliveira ${ }^{1}$, Surendraprabu Rangaraju ${ }^{1}$, Maarten Messagie $^{1}$, Joeri Van Mierlo ${ }^{1}$ \\ ${ }^{1}$ MOBI - Mobility, Logistics and Automotive Technology Research Centre, Vrije Universiteit Brussel,Belgium \\ luiolive@vub.ac.be
}

\begin{abstract}
The environmental performance of electrical vehicles is directly tied to the electricity mix that is used during the charging process. Nowadays, with a steady increase of renewable electricity being introduced, its usage is not always optimal. Alongside, its intermittent nature makes wind and solar not suitable for applications such as EV charging. Using a life cycle assessment methodology we analyze the impacts of the construction, usage and disposal/end of life of each of the studied systems. Pumped hydro and compressed air storage are studied as mechanical storage and advanced lead acid, sodium sulfur, lithiumion and nickel-sodium-chloride batteries are addressed as electrochemical storage systems. Hydrogen production from electrolysis and subsequent usage in a proton exchange membrane fuel cell is also analyzed. The functional unit is one kWh of energy delivered back to the grid/vehicle, from the storage system. The environmental impacts assessed are climate change, human toxicity, particulate matter formation, and fossil resource depletion. Different energy mixes are used in order to mimic scenarios where the environmental applicability of the technologies is put to the test. Results indicate that the performance of the storage systems is tied to the electricity source used during use stage. Renewable energy sources have lower impacts throughout the use stage of the storage technologies. Regarding infrastructure and end of life, battery systems have higher impacts than mechanical ones because of lower number of cycles and life time energy (9.000 fold). The environmental performance of the use stage of an EV fluctuates as the overall impacts of the supply mixes change with different storage technologies up to 32 fold.
\end{abstract}

Keywords: LCA, Energy Storage, Electrical Vehicle, Environment, Impacts

\section{Introduction}

Energy storage systems attached to renewable energy sources can shape their output and enable non-intermittent operation [1]. Energy mixes, still dominated by fossil and nuclear fuels do benefit the most by this symbiosis as the balancing needs of the electricity grid can be mitigated without using carbon based peak units such as turbo jets and coal based production plants. Electrical vehicle's (EV) environmental performance, Well-To-Tank WTT is totally dominated by the electricity production impacts [2]. Non-exhaust emissions such as brake wear, 
tire wear and road abrasion account for reduced environmental impacts during use stage (in the Tank-To-Wheel sub stage). Any apparent benefit to enhance (reduce) the impacts of the electricity production will directly prove fruitful for electrical vehicle overall environmental performance [3]. Nevertheless, an EV being used in a scenario where the electricity mix is reliant solely on carbon based (natural gas, oil, coal...) fuels will not have an environmental score much different than conventional internal combustion vehicles [4].

The case of Belgium electricity production unit portfolio can be highlighted by having a very moderate carbon footprint of roughly $183 \mathrm{~g}$ $\mathrm{CO}_{2} \mathrm{eq} \backslash \mathrm{kWh}$. It relies in nuclear energy (58.9\%), natural gas (27.74\%) and coal (4.6\%), according to 2011 data. Together, renewable energy sources account for $1,2 \%$, both photovoltaic and wind energy. With legislation forcing the decommissioning of nuclear plants, the electricity producers intend to increase significantly the share of renewable energy production units [3,4]. With this in mind, alongside the necessity to abandon the expensive, low efficient and non-environmental friendly production units, storage solutions such as lithium ion, sodium sulfur, lead acid and sodium nickel chloride batteries are assessed in this paper to validate their environmental viability under different scenarios of charging electricity mixes [5].

Renewable energy sources benefit from increased capacity factors as their output availability is increased by effect of the storage systems, shaping the amounts of electricity released to the grid. The storage systems also provide a change in the merit order, as they avoid the curtailment of the renewable sources in the system in the case of a traditional balancing strategy using peak units. The storage systems assume the role of a flexible production unit and with their storage buffer, balance the network.

Electricity mixes such as UCTE (2004), Belgium (2011), wind energy and photovoltaic energy are used to mimic different operational conditions [6]. Using a life cycle assessment perspective, the analysis is presented and the damages are quantified per product/service stage. The manufacturing, use stage and end of life of the storage systems are addressed under a descriptive and accurate direct assessment. The integrated system approach used demarks itself from literature studies as most often, they only include a reduced amount of compared technologies [7-
11]. Also, a hotspot analysis at material level is performed as a suggestion to the transmaterialization of battery materials in electrical vehicles. In this case, the life cycle inventory of a lithium ion, LFP, battery is used to demonstrate the individual impacts of each component.

\section{Methodology}

\subsection{Life Cycle Assessment}

Environmental life cycle assessment or is used to assess the overall environmental impact of a product or service by including all direct and indirect emissions. As a cradle-to-grave analysis, it takes into account everything from the raw material extraction, the processing, manufacturing, distribution, use phase, repairs and maintenances, and finally the disposal and/or the recycling of the product.

The ISO 14040 defines LCA as the "compilation and evaluation of the inputs, outputs and potential environmental impacts of a product system throughout its life cycle".

A LCA starts with the description of the primary service (PS) of a product. The primary service in this paper is the delivery of stored electricity. This primary service is then translated into a quantifiable functional unit. The functional is used as a reference unit in whole the study. It will also allow comparing similar product or services on a common, quantifiable basis. The results of a LCAstudy are directly related to the functional unit and will not reflect the overall absolute environmental impact.

A sound and solid LCA study has a series of defined phases which have to be followed and are described in the ISO 14040 and 14044, which are explained in more detail in the ILCD Handbook [12]. An LCA study is divided in: goal and scope definition, inventory analysis, impact assessment and interpretation [3].

\subsection{Goal and Scope Definition}

In order to increase the environmental performance of electrical vehicles, it is necessary to also increase the penetration of renewable energy sources. With the adoption of energy storage units, the system can acquire enough flexibility to balance itself without the need of traditional peak units such as turbo jets and gas turbines. This analysis consists on the assessment of the environmental performance of electricity storage 
systems suitable for grid attached storage which can potentiate the use stage of an electric vehicle. A cradle to grave analysis is performed including all of the servicelproduct stages. The analysis provides the necessary environmental input necessary to the decision making process on wither or not should energy storage systems be implemented for a specific application, under specific scenarios of electricity supply. The functional unit used will be $\mathrm{kWh}$, as it provides a quantified description of the functionality of the servicelproduct - In this case, to provide stored energy. The study boundaries comprehend every step from the extraction of raw materials (from anywhere in the globe), their processing and assembly, the transport to Belgium and finally, their use and end-of-life/disposal in Belgium. The distribution network for electricity was not included as the functional unit describes. The cutoff point in this case is the output of each of the storage systems. The energy mixes used throughout this study were the Belgium electricity mix for 2011 alongside with UCTE (from Ecoinvent 2.2) and both full photovoltaic and wind energy mixes (100\% wind, $100 \%$ PV) [13]. The impact assessment calculation methodology used is ReCiPe 2008 and the most relevant midpoint categories are assessed and compared [14]. The research this paper consists was performed under the framework of the FP7 Project 'Batteries 2020' of the European Commission.

\subsection{Software and Databases}

The software used to perform the modeling and calculate the impact assessment was SimaPro 7.3.3 (commercial analyst version) with Ecoinvent 2.2.1 database. The Impact assessment method selected in SimaPro is ReCiPe 2008.

The processes that were not found in the database were produced according to literature and real world data. Other processes from Ecoinvent were updated to reflect the actual scenarios used in the analysis.

\subsection{System Boundaries}

The system boundaries defined for the study comprehend the extraction and processing of raw materials for both energy and product components, the use phase (charge/discharge) and the end of life of the material after providing the products life time energy. As the analysis focus on the electricity storage at grid level, the comparison of two different electric vehicles would be redundant as the only different parameters would be in the Well-To-Tank stage. A description of the defined system boundaries can be found in Figure 1.

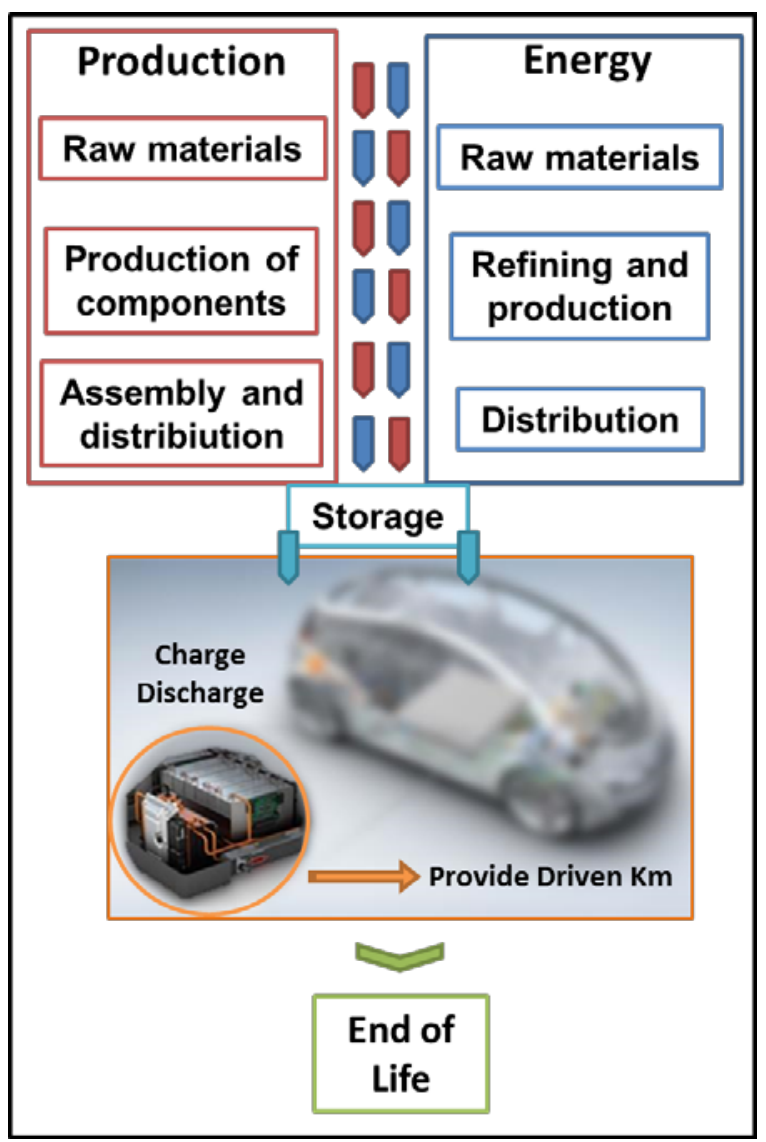

Figure 1: System boundaries

\section{Technical Specifications and Life Cycle Inventories}

\subsection{Characterization of RESS}

The technical characteristics of the Rechargeable Electricity Storage Systems (RESS) that are necessary to perform the modeling of the life cycle inventory concern power rating, capacity, life time and efficiency. After gathering several real world, already installed, storage unit information, it was possible to calculate the parameters and quantify them. The battery systems were assumed to be viable up to a $30 \%$ depth of discharge due to the nature of the application. With this in mind, Table 1 was produced in order to define the specifications [15]. 
Table 1 - Technical specifications of addressed systems

\begin{tabular}{|l|c|c|c|c|}
\cline { 2 - 5 } \multicolumn{1}{c|}{} & PbAc & Li-ion & NAS & NaNiCl \\
\hline $\begin{array}{l}\text { Lifetime } \\
\text { (years) }\end{array}$ & 5 & $5-10$ & $10-15$ & 10 \\
\hline Cycles & 1500 & 2500 & 3500 & 3500 \\
\hline $\begin{array}{l}\text { Total } \\
\text { kWh }\end{array}$ & $2.9 \mathrm{E}+06$ & $4.7 \mathrm{E}+06$ & $3.1 \mathrm{E}+07$ & $1.5 \mathrm{E}+07$ \\
\hline Eff. & $75 \%$ & $95 \%$ & $90 \%$ & $88 \%$ \\
\hline
\end{tabular}

\subsection{Life Cycle Inventories}

The life cycle of the lead acid and $\mathrm{NaNiCl}$ battery systems was sourced from the European Project SUBAT, on sustainable battery technologies and adapted to suit the application of grid support storage [15]. The lithium ion inventory, LMO chemistry, was produced inhouse, from the material analysis of cells [5]. The sodium sulfur inventory was sourced from Argonne National Lab's Energy Systems Division [16]. The inventories for electricity production were sourced from Ecoinvent, with the exception of the Belgium 2011 mix [4,17]

\section{Impact Assessment}

\subsection{Climate Change}

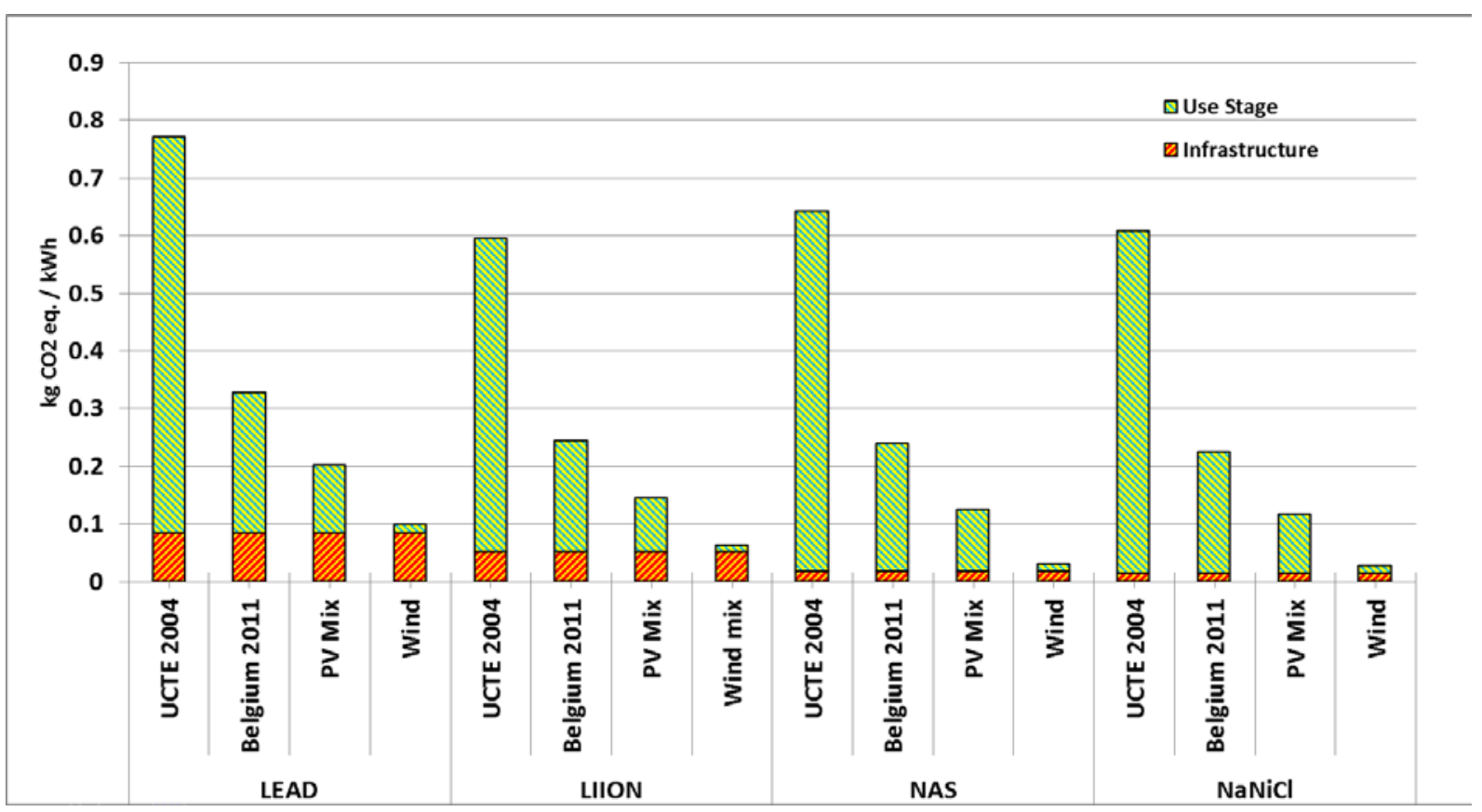

Figure 2: Contributions to Climate Change 


\subsection{Human Toxicity}

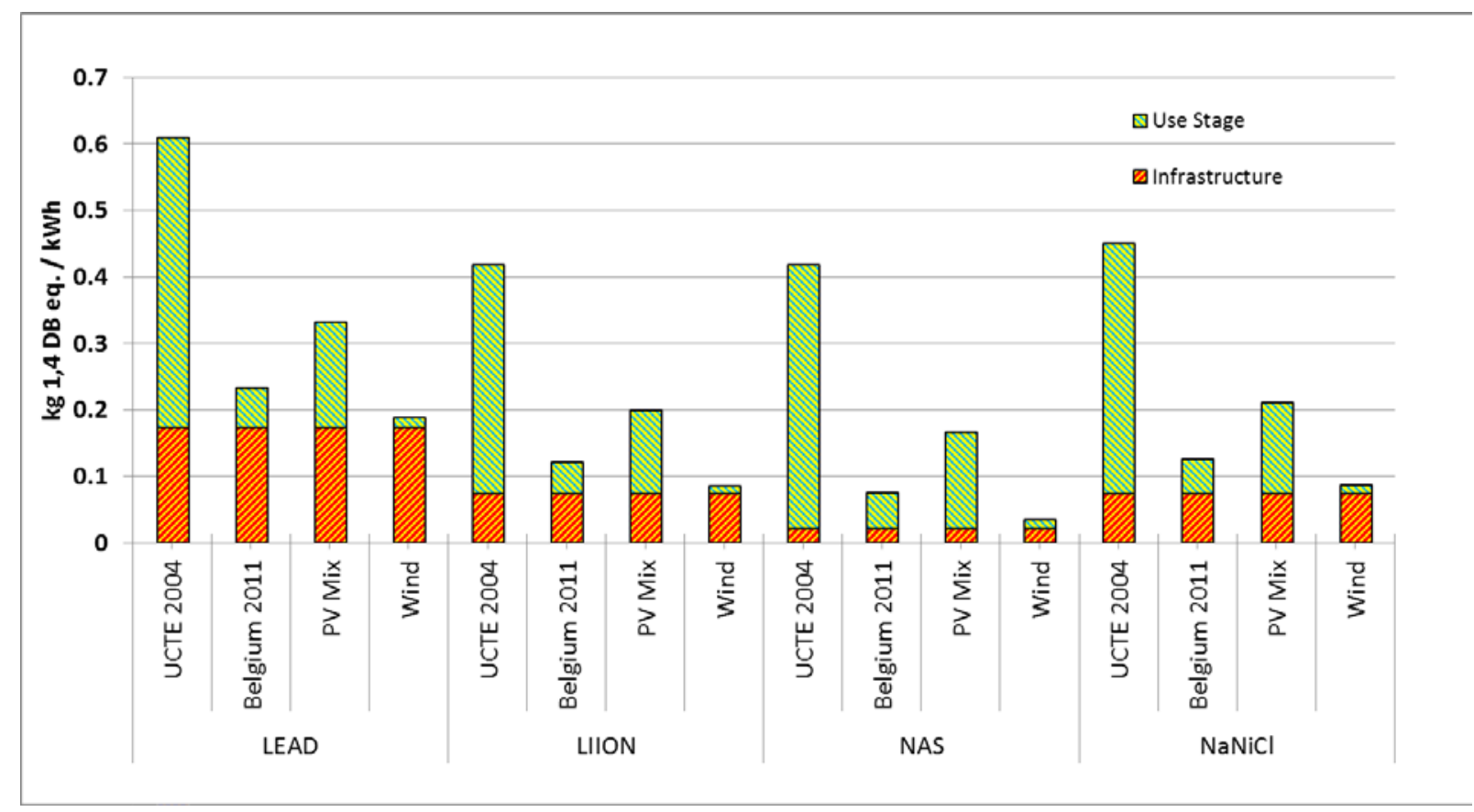

Figure 3: Contributions to Human Toxicity

Regarding human toxicity, it is difficult to outperform the average value for $1 \mathrm{kWh}$ produced using the 2011 Belgium electricity mix $(0,45$ $1,4 \mathrm{DB}$ eq./kWh). As indicated in figure 3 , only certain technologies where the production of the infrastructure does not contribute that much for this impact are able to achieve a lower score.

From the battery systems analyzed, the least performant is the lead acid battery, followed up by the $\mathrm{NaNiCl}$ system. The activities related to the mining of the materials needed to produce these batteries are the biggest contributor to the High score seen in figure 3. It is important to note the geographical dispersion of these impacts. Most of the times, the mining is performed in location A, transported to country B, Materials processed and then battery manufactured in country C. Finally, the use stage take place in country C, Belgium in our case. The case of high impacts from $\mathrm{NaNiCl}$ also originates from the high energetic process of mining Nickel. Again, not the mining associated damages of disposal of tailings, but the excessive energy used.

\subsection{Particulate Matter Formation}

Particulate Matter (PM) formation is mostly related to the release of fine dust particles originated from combustion processes or fugitive particles from energy feedstocks like coal. Secondary particulate formation is included (due to other gases condensing) as well contributions from other pollutants such as nitrogen oxides This aspect is reflected on the total quantity of energy used to process and produce some storage systems such as lead acid batteries, lithium-ion, sodium sulphur and $\mathrm{NaNiCl}$, as seen in Figure 4. The necessary bulk amount of energy necessary to have a ready-to-use system is so significant that it offsets the score of $\mathrm{NaNiCl}$ battery systems. In this case, the energy necessary to mine and process the nickel is the culprit of the high damage. The UCTE energy mix again proves to be the worst performer opposed to the full wind mix and relate perfectly to the system's charge/discharge efficiencies during the use stage. This overall high impact UCTE electricity production mix is mostly dependent in a high share of coal production units where the Belgian production mix for 2011 relies mostly (64\%) in nuclear based electricity production. 


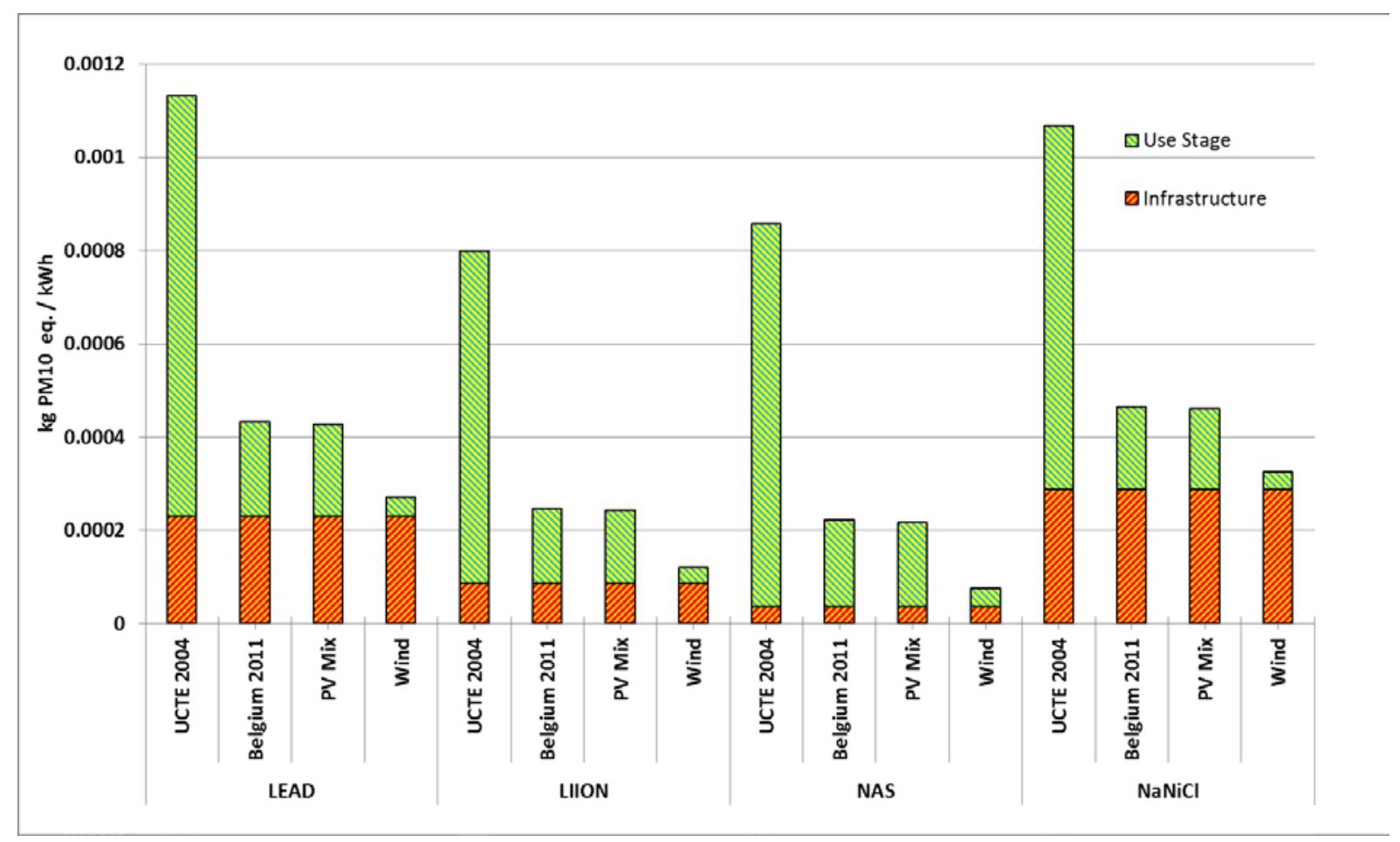

Figure 4: Contributions to Human Toxicity

\section{Hotspot Analysis}

After performing a hotspot analysis to a LFP battery, typical and go-to component of modern EV's, it is possible to identify several production stages and components to act upon. The modeled processes were broken down in transport, production infrastructure, manufacturing and assembly, energy, and battery materials.

Such an analysis, early in the development process and ecodesign of a battery storage system promotes the transmaterialization of the battery components towards a more environmental friendly materials and a cleaner production, fig.5.

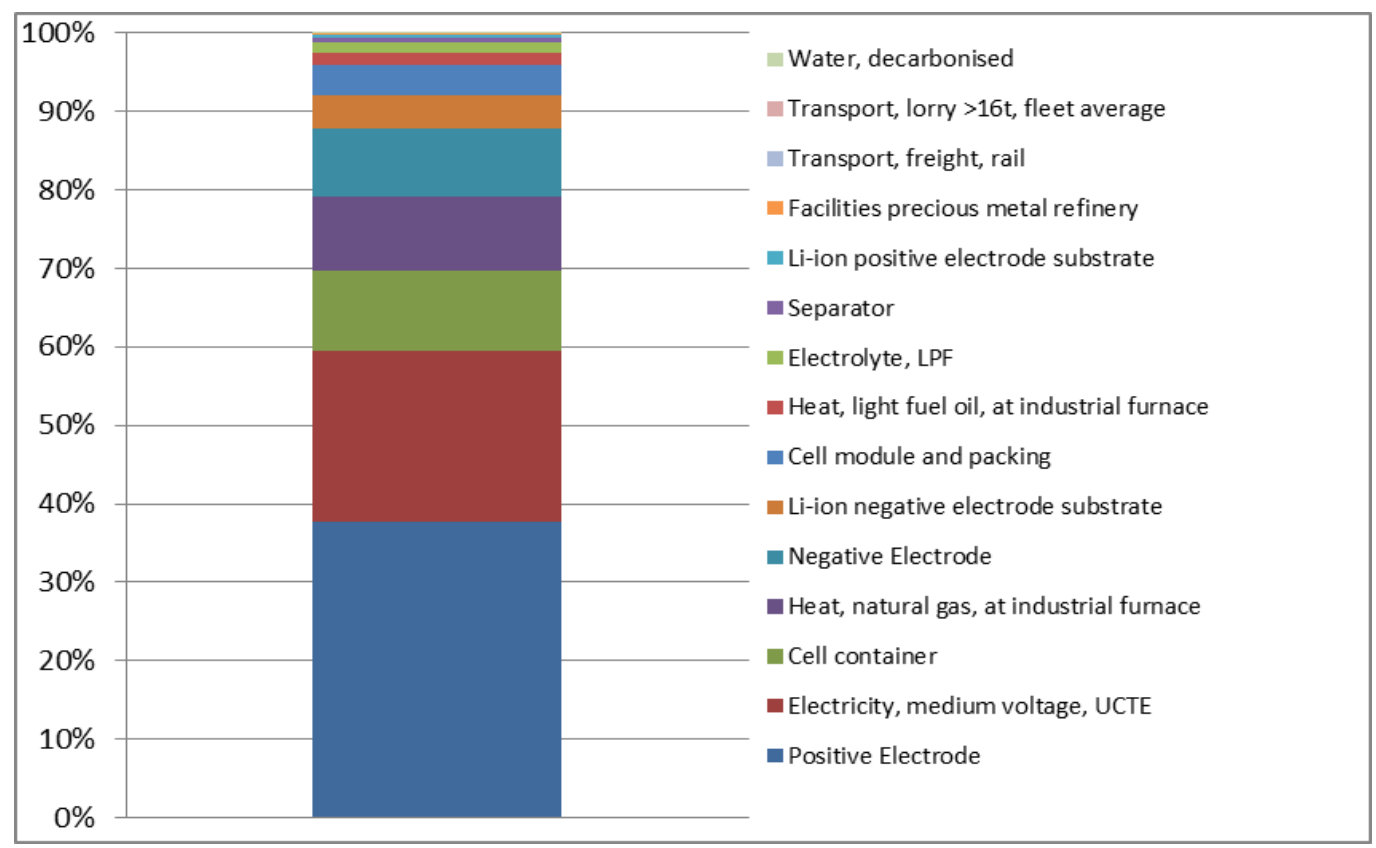

Figure 5: Environmental Stress per kWh of a LFP battery model (Climate Change) 
The three more contributing processes and materials, the positive electrode production accounts for $36 \%$ of the overall climate change impact related to infrastructure. With $21 \%$, the energy intensiveness of the manufacturing process is show with the "electricity, medium voltage, UCTE". The plastic cell container has a significant score of $9 \%$.

Aggregating all the processes in their respective categories, we observe on a dominance analysis the prevalence of impacts related to battery materials and used manufacturing energy, figure 6.

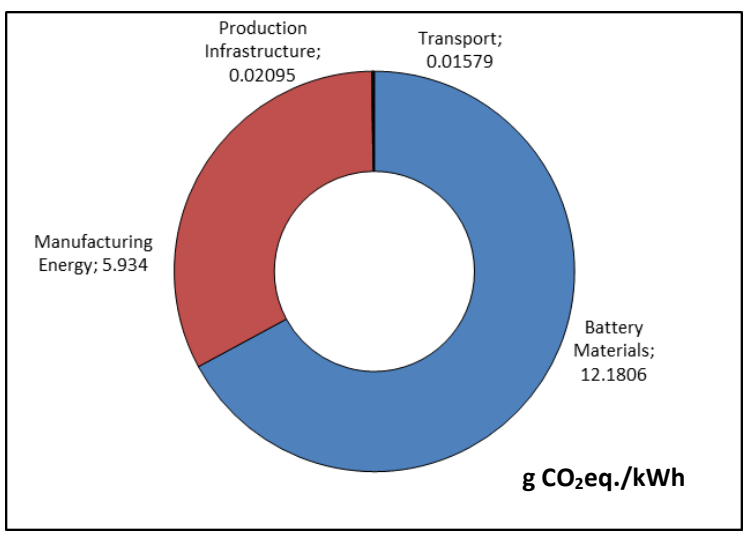

Figure 6: Dominance Analysis

\section{Conclusions}

The environmental performance of energy storage systems is directly tied to their efficiency and the nature of the manufacturing processes and materials used. The importance of the electricity mix used to provide energy to these systems defines under a life cycle approach, the environmental damages. Using carbon intensive electricity production portfolios will naturally lead to more damaging effects while using renewable electricity production units such as wind and PV are if not always, most of the times the best option.

It is clear that using these renewable units, alongside with energy storage systems, and avoiding traditional peak units, the environmental performance of electrical vehicles, which on a WTT pathway, only rely on electricity production and delivery, will be lower.

Analyzing the results and their values, it is possible to observe different opportunities to reduce climate change impacts by using high efficiency storage units, Li-ion, $\mathrm{NaNiCl}$ and NAS. In the case of human toxicity, high volume, moderate efficiency systems, sodium sulfur batteries. Concerning PM formation, if it is chosen to reduce overall dust emissions, the only solution is to store energy originating from wind farms. This happens due to the fact that with every other mix, even full PV, the scores sit well above the average impact. .

When using renewable energy production mixes such as wind, the relevance of the technical aspects such as capacity, lifetime, efficiency dispatchability and costs prove more important than the environmental performance itself. All the technologies perform very well, bellow threshold levels with a $100 \%$ wind electricity mix, where the differences are neglectable (in the particular cases where solely the infrastructure impacts do not sit above the benchmark thresholds).

With the dominance analysis it is safe to say that further development should be oriented to reducing environmental impacts of battery materials, mostly cathode and anode. The energy intensiveness of the production/manufacturing stage should be further reduced using new methods or, by using renewable energy sources, stabilized be the usage of energy storage systems.

\section{Acknowledgments}

The authors acknowledge Flanders Make for the support to our team. We also acknowledge the BATTERIES 2020 FP7 Project funded by European Commission for the support to this project.

\section{References}

[1] - Marc Beaudin et al., Energy storage for mitigating the variability of renewable electricity sources: An updated review, Energy for Sustainable Development, Volume 14, Issue 4, December 2010, Pages 302-314, ISSN 0973-0826, http://dx.doi.org/10.1016/j.esd.2010.09.007.

[2] - A. Nordelöf, et al., "Environmental impacts of hybrid, plug-in hybrid, and battery electric vehicles-what can we learn from life cycle assessment?,” Int. J. Life Cycle Assess., Aug. 2014.

[3] - Messagie et al., A Range-Based Vehicle Life Cycle Assessment Incorporating Variability in the Environmental Assessment of Different Vehicle Technologies and Fuels, Energies 2014, 7(3), 1467-1482; doi:10.3390/en7031467

[4] - Messagie et al., The hourly life cycle carbon footprint of electricity generation in Belgium, bringing a temporal resolution in life cycle assessment. Applied Energy 2014, 134, 469 
[5] - Sanfélix et al., Environmental performance of advanced hybrid energy storage systems for electric vehicle applications. Applied Energy 2015, 137, 925.

[6] - Messagie et al.,The Influence of Allocation on the Carbon Footprint of Electricity Production from Waste Gas, a Case Study for Blast Furnace Gas, Energies 2013, 6(3), 1217-1232; doi:10.3390/en6031217

[7] - Denholm et al., Life cycle energy requirements and greenhouse gas emissions from large scale energy storage systems, Energy Conversion and Management, Volume 45, Issues 13-14, August 2004, Pages 2153-2172, ISSN 0196-8904, http://dx.doi.org/10.1016/j.enconman.2003.10.01 4.

[8] - Hartikainen et al., Environmental advantages of superconducting devices in distributed electricitygeneration, Applied Energy, Volume 84, Issue 1, January 2007, Pages 29-38, ISSN 0306-2619, http://dx.doi.org/10.1016/j.apenergy.2006.04.011

[9] - Rubio et al., An LCA based indicator for evaluation of alternative energy routes, Applied Energy, Volume 88, Issue 3, March 2011, Pages 630-635, ISSN 0306-2619, http://dx.doi.org/10.1016/j.apenergy.2010.08.013

[10] - Chicco et al., Distributed multi-generation: A comprehensive view, Renewable and Sustainable Energy Reviews, Volume 13, Issue 3, April 2009, Pages 535-551, ISSN 1364-0321, http://dx.doi.org/10.1016/j.rser.2007.11.014

[11] - Tan et al., Advances and trends of energy storage technology in Microgrid, International Journal of Electrical Power \& Energy Systems, Volume 44, Issue 1, January 2013, Pages 179-191, ISSN 0142-0615,

http://dx.doi.org/10.1016/j.ijepes.2012.07.015

[12] - European Commission - Joint Research Centre Institute for Environment and Sustainability. (2011) - International Reference Life Cycle Data System (ILCD) Handbook - Recommendations for Life Cycle Impact Assessment in the European Context. DOI:10.2788/38479

[13] - Ecoinvent Database, http://www.ecoinvent.org accessed from 1/2/2013 to 15/1/2014

[14] - Goedkoop et al.ReCiPe 2008 - A life cycle impact assessment method which comprises harmonized category indicators at the midpoint and the endpoint level, First edition. Report I: Characterization. http://www.lcia-recipe.net.

[15] - Van den Bossche et al., SUBAT: An assessment of sustainable battery technology, Journal of Power Sources, Volume 162, Issue 2, 22 November 2006, Pages 913-919, ISSN 03787753,

http://dx.doi.org/10.1016/j.jpowsour.2005.07.039
[16] - A Review of Battery Life Cycle Analysis: State of Knowledge and Critical Needs, Energy Systems Division, Argonne National Laboratory, 2010, ANL/ESD/10-7

[17] - Frischknecht et al., Life Cycle Inventories of Electricity Mixes and Grid. ESU-services Ltd: Uster, Switzerland 2013.

\section{Authors}

Luis Oliveira* concluded his studies in the Superior Engineering Institute of Porto - ISEP, (Portugal) in the area of Mechanical Engineering in 2010 and becomes a year later, Master in Electromechanical Engineering at Karel de Grote Hogeschool in Antwerp, specializing in particulate matter filtering. In 2011 starts research at the Lung Toxicology Unit of the Public Health and Insurance Medicine Department of KU Leuven on the health effects of inhaled nanoparticles created in the combustion of diesel based fuels. In October 2012 starts his PhD. in Engineering Sciences at Vrije Universiteit Brussel while conducting research on several projects related to Life Cycle Assessment, focusing in energy storage systems, more specifically, Lithium Batteries for traction systems.

Surendraprabu Rangaraju is a research associate in environmental assessment team within the MOBI research group led by Prof.Dr.Joeri Van Mierlo. He obtained his master degree in Energy and Environmental Engineering, at the Department of Mechanical Engineering, Linkoeping University, Sweden. He is currently researching on the environmental aspects of intermittent renewable energy sources, namely wind and photovoltaic.

Maarten Messagie is an engineer specialized in industrial development. He obtained a Master degree in sustainable development (VUB) and specialized himself in environmental assessment methodologies as trainee in an environmental consultancy agency and as $\mathrm{PhD}$ student in Aalborg University and the University of Trondheim (NTNU). Currently he is 
an environmental researcher for the MOBI team working on environmental assessments (Well-toWheel and Life Cycle Assessment) of the transport and energy sector in various national and international projects. His main focus is on

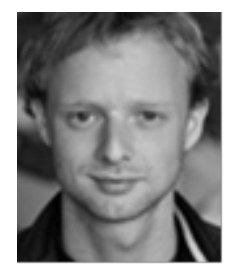
conventional and alternative vehicles, with a special interest for electric and hybrid cars. His research interests are alternative vehicle technologies, Life Cycle Assessment methodology, Ecodesign and sustainable energy systems.

Prof. Dr. ir. Joeri Van Mierlo obtained his Ph.D. in electromechanical Engineering Sciences from the Vrije Universiteit Brussel in 2000. He is now a full-time professor at this university, where he leads the MOBI - Mobility and automotive technology research centre (http://mobi.vub.ac.be). Prof. Van Mierlo is visiting professor at Chalmers University of Technology, Sweden (2012). He is expert in the field of electric and hybrid propulsion systems (power converters, energy storage, energy management, etc.) as well as to the environmental comparison of vehicles with different kinds of drive trains and fuels (LCA, WTW). Prof. Van Mierlo is Vicepresident of AVERE (www.avere.org), is the secretary of the board of the Belgian section of AVERE (ASBE) (www.asbe.be). He chairs the EPE chapter "Hybrid and electric vehicles" (www.epeassociation.org). He is member of ERTRAC's Energy \& Environment Working Group (European Research Transport Advisory Council). He is an active member of EARPA - the European Automotive Research Partner Association and IEEE senior member as well. 